EPJ Web of Conferences 47, 16001 (2013)

DOI: $10.1051 /$ epjconf/20134716001

(C) Owned by the authors, published by EDP Sciences, 2013

\title{
Introduction to EU Grants and Fellowships for PhD students and early Post-docs
}

Julia Epp ${ }^{\mathrm{a}}$

Max-Planck-Institute of Quantum Optics, Hans-Kopfermann-Str. 1, 85748 Garching, Germany

\begin{abstract}
This talk is based on the presentation "Introduction to EU Grants and Fellowships for PhD students and early Post-docs" and aims at informing young scientists about individual funding schemes in FP7 Specific Programmes "People" and "Ideas". It also aims at encouraging young scientists employed at Max Planck Institutes in the "Regional Cluster Bavaria", or scientists who wish to come to Max Planck Institutes which are part of the cluster, to benefit from the support of the Regional EU Office Bavaria, whose consultants can give valuable administrative and tailor-made internal advice to add on the success of a competitive scientific proposal.
\end{abstract}

The EU Office of Max Planck Institutes in Regional Cluster Bavaria [1] currently supports six Max Planck Institutes in Bavaria, i.e. MPI for Astrophysics, MPI for extraterrestrial Physics, MPI of Physics, MPI of Psychiatry, MPI of Quantum Optics and MPI for Ornithology. Scientists can contact the EU Office Bavaria for support in proposal preparation if they are employed at one of these institutes, or if they plan a proposal with one of these institutes as host institution.

The EU Office Bavaria supports these institutes with information about EU programmes, analyses project ideas and helps scientists to find the right funding scheme, assists with proposal preparation, checks proposals, and provides support in project management. The EU Office Bavaria also organizes talks, events and conferences for these institutes, also in the framework of EU projects in which they act as coordinator or partner.

After a short introduction to the background of European research funding, we will essentially focus on the current EU funding schemes young researchers can apply to and how they can get supported by the EU Office Bavaria.

\section{SOME BACKGROUND ABOUT EUROPEAN RESEARCH FUNDING}

If we think about our situation in Europe today, where we can freely circulate between countries and pay with a common currency in many countries, we realize that, also for European research, there exists a concept to overcome fragmentation and, among others, to facilitate free circulation for researchers: the European Research Area (ERA) [2]. One important instrument to reach the objectives of ERA is the EU's Research Framework Programme, currently the Seventh Framework Programme (FP7, 2007-2013) [[2], p.5]. The Seventh Framework Programme contributes to the creation of the European Research Area by several sub-objectives, among others by strengthening the "human potential in research and technology in Europe" and by fostering "dynamism, creativity and excellence of European research" [[3], p.2]. These sub-objectives are reflected by so-called Specific Programmes of FP7: the "People" Programme supports individual researchers and the "Ideas" Programme fosters "investigator-driven research based on the initiative of the research community", respectively [[3], p.2]. We will focus

\footnotetext{
${ }^{a}$ e-mail: julia.epp@mpq.mpg.de
}

This is an Open Access article distributed under the terms of the Creative Commons Attribution License 2.0, which permits unrestricted use, distribution, and reproduction in any medium, provided the original work is properly cited. 
on these two programmes, as in both the research topics to be submitted can be chosen freely by the scientists themselves, contrary to other Specific Programmes with "policy-defined themes" like the "Cooperation Programme" [[3], p.2]. We also draw young scientists" attention in particular to the "People" and the "Ideas" Programme as both of them support individual scientists, or "individual teams" [[3], p.27]. We will focus in particular on funding schemes where an individual, together with a host institution, can apply for funding.

\section{INDIVIDUAL FUNDING SCHEMES IN THE "PEOPLE" PROGRAMME}

The activities in the FP7 Specific Programme "People" are also known as "Marie Curie Actions" [[4], p.276]. When informing about relevant funding schemes, the EU Office Bavaria refers to the current work programme [[4], p.278] which implements the Specific Programme. In this case, we refer to the "People" work programme 2013. According to this programme, "the overall strategic objective is to make Europe more attractive for researchers. The Specific Programme aims to strengthen, quantitatively and qualitatively, the human potential in research and technology in Europe, by stimulating people to take up the profession of a researcher, encouraging European researchers to stay in Europe, and attracting to Europe the best researchers from the entire world" [[5], p.4]. To give young scientists an orientation of whether or not they are eligible to apply for funding schemes in this programme, we refer to two basic concepts laid out in the programme: the concept of research experience and the mobility rule.

\subsection{Early-stage researcher vs. Experienced researcher}

The 2013 "People" work programme distinguishes between the Early-stage researcher who "shall [...] be in the first four years (full-time equivalent research experience) of their research careers and have not yet been awarded a doctoral degree" and the Experienced researcher who "shall, at the time of the relevant deadline for submission of proposals(IEF, IIF, IOF, CIG) [...] be in possession of a doctoral degree or have at least four years of full-time equivalent research experience" [[5], p.8]. We invite young scientists to carefully check which category is the appropriate one for him/her. The funding schemes presented in section 2.3 are all targeted to Experienced researchers.

\subsection{The Mobility rule}

The 2013 "People" work programme states that "at the time of the relevant deadline for submission of proposals [...] researchers shall not have resided or carried out their main activity (work, studies, etc) in the country of their host organisation for more than 12 months in the 3 years immediately prior to the reference date. Compulsory national service and/or short stays such as holidays are not taken into account. As far as international European interest organisations or international organisations are concerned, this rule does not apply to the hosting of eligible researchers. However the appointed researcher shall not have spent more than 12 months in the 3 years immediately prior to the reference deadline for submission of proposals or recruitment by the host organisation, depending on the action, in the same appointing organisation" [5], p.8]. Before applying to funding schemes, scientists should carefully check if they comply with this rule and or consult the EU Office Bavaria for advice if their individual situation meets these requirements.

\subsection{Individual funding schemes targeted at Experienced researchers}

The individual funding schemes Intra-European Fellowship (IEF), International Outgoing Fellowship (IOF), International Incoming Fellowships (IIF) and Career Integration Grant (CIG) which will be exposed more in detail below are targeted at Experienced researchers [[5], p.16,23,24,34]. Our 


\section{Hot Planets and Cool Stars}

experience in consulting scientists shows that applicants for individual Marie Curie funding schemes tend to be rather young, when disposition for mobility seems to be higher than at a more advanced age. All four funding schemes require trans-national mobility [[5], p.16,23,24,34]. To better illustrate when a scientist can apply to these actions, we look at four different mobility situations.

\subsubsection{Mobility from a European country to another European country}

A scientist is currently working in a EU Member State or Associated Country to FP7 [6] and would like to carry out research in a particular institution in another EU Member State or Associated country in order to advance in his/her scientific career. In this case, we recommend scientists to apply for the IntraEuropean Fellowship (IEF). The IEF provides funding for 1-2 years. The fellowship's objective is to support the career development or restart through competence diversification (multi- or interdisciplinary expertise, intersectoral experience, complementary skills...) in order to reach and/or reinforce a position of professional maturity/independence [[5], p.16].

\subsubsection{Mobility from a European country to a non-European country and back to Europe}

A scientist is currently working in a a EU Member State or Associated country [6] and would like to temporarily carry out a research project in "another third country" [[5], p.8], with the perspective to terminate this project in Europe. In this case, we would recommend to apply for the International Outgoing Fellowship (IOF) [[5], p.23,24]. The IOF is designed to reinforce the international dimension of a research career and to advance towards professional maturity and independence: acquire new competences such as multi- or interdisciplinary expertise, intersectoral experience, complementary skills. It is divided into an outgoing phase (1-2 years) and a subsequent, mandatory reintegration phase in a EU Member State or Associated country. Third country nationals (not from EU Member States or Associated States) are eligible to apply if they have resided and carried out their main activity in Europe for at least the 5 years prior to the submission deadline. The Mobility rule applies to the outgoing host organisation [[5], p.23,24,39]. This means that a scientist could spend the reintegration phase in the same European country, or even the same institution, in which he/she has resided before submitting the proposal. The proposal is submitted with the return host institution. Applicants should note that this fellowship scheme requires quite a lot of anticipation - contacts with the return host organisation, where the potential fellow will be hosted in only around three years time at the moment of proposal submission, have to be established well in advance. However, this should be natural as a coherent research project is proposed for the overall duration of the IOF.

\subsubsection{Mobility from a non-European country to a European country}

A scientist who is currently working in "another third country" [[5], p.8] and would like to work in research in a EU Member State or Associated country could possibly apply for the International Incoming Fellowship (IIF). The focus of the IIF is different from IEF and IOF, which support the career development of the fellow. The IIF aims at reinforcing scientific excellence of host institutions in EU Member States and Associated countries, by sharing knowledge with them and developing mutually beneficial research cooperations [[5], p.24]. The duration of this fellowship is 1-2 years. Nationals from International Cooperation Partner Countries (ICPC) [[5], p.52] can apply additionally for a subsequent reintegration phase, which is funded with a flat rate contribution of 15.000 EUR [[5], p.41,70]. All three fellowships include a monthly living and mobility allowance, contributions to the training of the fellow (IEF, IOF) or the knowledge transfer (IIF) and a contribution to overheads which are (except of the contribution to training or knowledge transfer) adjusted by a country correction coefficient [[5], p.70]. 


\subsubsection{Mobility from a European country to another European country because of a job offer}

Another possible situation is that a scientist will undertake trans-national mobility at European level because he/she has been offered a position in another country. If the applicant has been offered an employment contract for at least a few years, we would encourage him to apply for the Career Integration Grant (CIG). The CIG is dedicated to improve the career prospects of researchers who have been offered a (permanent) position in Europe after a mobility period, in order to contribute to the researcher's integration. The condition is that the applicant's employment contract covers at least the duration of the CIG. The CIG can last for a maximum of four years. Another condition is that the applicant cannot have benefited from another FP6 or FP7 Reintegration grant before. The funding comprises a fixed-amount contribution to the employment and/or research costs of 25.000 EUR/year [[5], p.17,34].

\section{INDIVIDUAL FUNDING SCHEME ERC STARTING GRANT IN THE “IDEAS" PROGRAMME}

Another funding scheme which should briefly be mentioned in a young scientists' meeting such as the RoPACS final conference is the Starting Grant of the European Research Council (ERC) [[7], p.18]. As the EU Office Bavaria always advises to plan the research career on a long-term basis, we stress the importance that young scientists should have at least heard about the existence of such a scheme, even if the fellow is not yet eligible to apply.

The ERC Starting Grant is targeted to researchers who are about to start their own independent research team or programme. In the last call, researchers after 2 and up to 7 years past $\mathrm{PhD}$, counting backwards from the publication date of the call, were eligible to apply for funding of up to 1.5 Mio. EUR, in exceptional cases even up to 2 Mio. EUR for a duration of up to 5 years [[7], p.19]. Our experience in consulting ERC Starting Grant applicants - whose proposals have been successful - has shown that they often have benefited from at least one Marie Curie fellowship or similar national funding scheme when they prepare an application. Therefore, we might conclude that the Marie Curie fellowships or similar national funding might be a logical pre-stage to a successful ERC Starting Grant application. The central objective of all ERC funding schemes is "to reinforce excellence, dynamism and creativity in European research" [[7], p.5], therefore, the sole criterion for selection is scientific excellence [[7], p.8].

\section{PROPOSAL STRUCTURE OF FP7 FUNDING SCHEMES, EVALUATION CRITERIA OF MARIE CURIE FELLOWSHIPS, TIME LINE AND PROPOSAL SUBMISSION}

After having exposed some important individual funding schemes from the "People" and "Ideas" Specific programmes which we consider as the most relevant ones for young scientists, we have a look at the proposal structure, which is the EU Office's main field of intervention in the application phase. All EU proposals are structured in an A "administrative" part and B "scientific proposal". Further information is given in the Guide for Applicants [[5], p.32]. As the regional EU Office Bavaria is an internal Max Planck consulting structure for Max Planck Institutes, it is a unique point of contact when seeking help to fill out the A forms, which require input of internal information about the host institution. By consulting the EU Office Bavaria from the beginning or even filling in the forms together with one of our consultants can save researchers valuable time. The EU Office Bavaria also advises on part B issues, in the first place on formalities, but also on style and structure. In Marie Curie fellowship proposals, which contain several non-scientific chapters which are subject to evaluation (such as implementation, impact etc.) [[5], p.57] we can also provide valuable input. Here again, researchers benefit from the internal knowledge and integration in the Max Planck Bavarian research landscape: we can provide input if a Max Planck Institute offers language courses, if there is a particular welcome structure, which person at the particular institute takes care of administrative issues such as visa, bank accounts etc. 


\section{Hot Planets and Cool Stars}

Our experience has shown that this "trivial" information is often neglected but can substantially add to the necessary score to get funded. The importance of the non-scientific criteria is reflected in the weightings and thresholds of the evaluation criteria: For the IEF, the scientific and technological quality is weighted $25 \%$ and has a threshold of 3 , the training is weighted $15 \%$ and has a threshold of 3 , the chapter "Researcher" is weighted $25 \%$ with a threshold of 4 , the implementation of the project is weighted with $15 \%$, the impact is weighted with $20 \%$ and has a threshold of 3.5 points [[5], p.57]. When advising scientists, we give an overview of the timeline of proposal preparation, evaluation and contract negotiation, reflecting the experience of the past: Proposal submission for Marie Curie fellowships is usually mid-August [[5], p.29]. We can conclude from this time line that there can be easily one year between proposal submission and start of the project, depending on the start date chosen. Last but not least, we give information about the Research Participant Portal where all relevant information such as work programmes, Guides for Applicants and the link to electronic proposal submission can be found [8]. Finally, the EU Office Bavaria draws the researchers' attention to the EU's EURAXESS website, by pointing out that here also positions in FP7-funded "host-driven actions" are advertised, among other positions. Everyone planning trans-national mobility will find valuable information with many links to practical information for a particular country. Also, we mention the importance the EU gives to the rights of a researcher, to which EURAXESS dedicates a special part of the website [9].

\section{References}

[1] www.mpq.mpg.de/eubuero-bayern

[2] $\operatorname{COM}(2007)$ 161, ERA Green Paper: The European Research Area: New Perspectives

[3] OJ L 412, Decision No 1982/2006/EC of the European Parliament and of the Council of 18 December 2006 concerning the Seventh Framework Programme of the European Community for research, technological development and demonstration activities (2007-2013)

[4] OJ L 400/276, Council Decision of 19 December 2006 concerning the specific programme People implementing the Seventh Framework Programme of the European Community for research, technological development and demonstration activities (2007 to 2013)

[5] European Commission C(2012)4561, 2013 Work programme "People", European Commission C(2012)4561 of 9 July 2012

[6] FP7 Third Country Agreements, ftp://ftp.cordis.europa.eu/pub/fp7/docs/third_ country_agreements_en.pdf

[7] European Commission C(2012) 4562, The "Ideas" Work Programme/European Research Council 2013 Work Programme, European Commission C(2012) 4562 of 09 July 2012

[8] Research Participant Portal, http://ec.europa.eu/research/participants/portal/ page/home

[9] EURAXESS, http://ec.europa.eu/euraxess/ 